\title{
A Review on Biofortification - To Improve Nutritional Quality of Cereals
}

\author{
Madhu Choudhary* and Rajwanti Saran
}

Division of plant breeding and genetics, Rajasthan Agricultural Research Institute (S.K.N. Agriculture University, Jobner), Durgapura, Jaipur-302018 (Rajasthan), India

*Corresponding author

\section{Ke ywords \\ Biofortification, Nutritional quality, Cereals \\ Article Info \\ Accepted: \\ 17 August 2020 \\ Available Online: \\ 10 September 2020}

\begin{abstract}
A B S T R A C T
Biofortification is a probable and cost-effective means of providing micronutrients to populations that may have limited access to diverse diets and other micronutrient intercession. Micronutrient deficiency, also known as 'hidden hunger' is one of the most important provocations facing humanity today. According to world health organization (WHO) report about 3 billion people worldwide suffer from micronutrients deficiency. In India, malnutrition problems like anaemia about more than 52\% of women suffer, $44 \%$ of children below 5 years are underweight and $38 \%$ are stunted. Therefore, to overcome the malnutrition in human beings, improvement of crop quality by bio-fortification process for important crop plants through biotechnological applications that is sustainable solution. Target crops for increase micronutrient status like rice and maize for Fe, Zn, Pro-vitamin A and wheat, pearl millet, sorghum, small millets for $\mathrm{Zn}$ and Fe. Two approaches for biofortification i.e., agronomic and genetic used to increase nutrients level in stable food crops. Bio-fortified crop varieties are developed by plant breeding using selective breeding and genetic modification. In wheat recreated synthetics, wild relatives and landraces are being used as progenitor for high $\mathrm{Zn} / \mathrm{Fe}$ source and approaches are backcross, bulk scheme and wide-cross uses for development of fortified varieties. Pearl Millet, as a species, has higher levels of $\mathrm{Fe}$ and $\mathrm{Zn}$ densities than other major cereal crops many varieties developed in pearl millet. The development of the 'golden rice' proved that biofortified crop developed through genetic engineering. In maize QPM is a product of conventional plant breeding (i.e., it is not genetically modified) it produces $70-100 \%$ more of lysine and tryptophan than the most modern varieties. Given the severity of mineral malnutrition in humans worldwide, biofortification of micronutrients, especially $\mathrm{Fe}$ and $\mathrm{Zn}$, in cereals must be encouraged.
\end{abstract}

\section{Introduction}

Biofortification is a Greek word "bios" means life and Latin word "fortificare" means make strong. Biofortification refers to increasing genetically the bioavailable mineral content of food crops (Brinch-Pederson et al., 2007).
Anaemia is the most common human malnutrition, resulting from iron $(\mathrm{Fe})$ deficiency and affecting $32.9 \%$ people worldwide meanwhile, zinc $(\mathrm{Zn})$ deficiency affects $17 \%$ of the world's population (Wessells et al., 2012; Kassebaum et al., 2014). In the twenty-first century, there is 
strong trouble worldwide concerning the ability to produce nutritionally rich food because cereals are inheritably poor in essential micronutrients. Moreover, owing to grow a rapidly human population and industrialization; this situation may be further being composed of by the production of cereals in areas with low mineral phytoavailability (White and Broadley, 2009). Hence, malnutrition and poor health affect these people, who may suffer from blindness or stunting, and sometimes even face death. To overcome this "hidden hunger" through medical supplements and fortification have been pursued (Underwood, 2000). In fact, food fortification has a long history of use in industrialized countries and perceive on the addition of micronutrients to processed foods. However, food fortification tends to have a rapid but less sustainable impact, because various safety, technological and cost considerations may place restriction on such interventions (Allen et al., 2006). By increasing the micronutrient content of energy-rich crops, micronutrient intakes among the poor can be increased, thereby leading to decreases in the prevalence of micronutrient deficiencies. It differs from ordinary fortification because it focuses on making plant foods more nutritious as the plants are growing, rather than having nutrients added to the foods when they are being processed. Traditionally, vitamins and minerals have been provided to the masses through nutrient supplementation programs, but it falls short of the goals set by the international health organizations as the supplementation programs rely on external funding that is not guaranteed to be available from year to year. Other limitations are purchasing power of poor people, their access to markets and health-care systems, and lack of awareness regarding the long-term health benefits of these nutrient supplements. Hence, biofortification of different crop varieties offers a sustainable and long-term solution in providing micronutrients-rich crops to people. Furthermore, biofortified crops with increased bio available concentrations of essential micronutrients are deployed to consumers through traditional practices used by agriculture and food trade which therefore provides a feasible way of reaching undernourished and low income group families with limited access to diverse diets, supplements and fortified foods.

\section{Malnutrition data}

Malnutrition form an important global health issue, affecting key development outcomes including poor physical and mental development in children, vulnerability of disease, mental retardation, blindness and general losses in productivity and potential. The World Health Organization (WHO) estimate 3 billion people worldwide suffer micronutrients deficiency, hunger and undernourishment, which is defined as dietary energy intakes below the minimum levels necessary to achieve and maintain a healthy weight, over nourishment, which is defined as dietary energy intake which exceeds requirements for maintenance of a healthy bodyweight, micronutrient deficiencies, which is defined as a lack of essential vitamins and minerals required in small amounts by the body for proper growth and development.

Zinc deficiency can have a number of negative health consequences, affecting the central nervous, immune, reproductive, and skeletal systems. Zinc is an essential nutrient for growth and recovery deficiencies can therefore stunt growth, increase susceptibility to disease and infection, increase recovery time, or in some cases, impair recovery, reduce mental capacity, and increase the prevalence of maternal, new born and child complications higher morbidity and mortality in mothers (Prasad et al., 2013). Generally, 
recommended dietary allowance for $\mathrm{Zn}$ is around $15 \mathrm{mg}$ per day (National Research Council 1989). About 2.5 billion world population suffer from Zinc deficiency (Oliver and Gregory, 2015).

About 400 million people have vitamin A Deficiency, 1.6 billion populations suffer from Iron deficiency globally and anaemia affects more people than any other health problem. Anaemia has important implications for general productivity and development, reducing the work capacity of individuals by up to 20 percent (Welch and Graham2015).

India is one of the countries having problem of malnutrition more than $52 \%$ of women, $44 \%$ of children below 5 years are underweight and $38 \%$ are stunted. As per India state hunger index (ISHI), all the states are with serious to alarming, in which Madhya Pradesh most alarming. The World Bank estimates that India is one of the highest ranking countries in the world for the number of children suffering from malnutrition. As per the Global Hunger Index, 2018 (GHI), published on October 10, 2018, the level of hunger and under nutrition worldwide fell to 20.9, down from 29.2 in the year 2000. As per the index, India was ranked 103rd out of 119 qualifying countries (World Bank).

\section{Importance of crop biofortification}

Biofortification on staple foods could be a more sustainable approach, also suitable for remote regions. Biofortified crops can potentially provide iron, zinc and vitamin A to people with limited connection to commercial markets (Mayer et al., 2008).

The suitability of biofortification for the poor, who mainly eat staples that are not commercially processed and sold but depend on household produced crops, is the most notable advantage (Tanumihardjo et al.,
2008). Thus, biofortification has the potential to reduce the preponderance of micronutrient deficiencies and lower the number of people requiring intercession such as fortification and supplementation to increment of nutritional quality in diets (Bouis and Welch, 2010). In contrast to dietary diversification, no behavioural changes are required from the consumers. However, the target crop has to be select carefully, following the dietary patterns of the consumers (Qaim et al., 2007).

The acceptance of the newly developed crop by the targeted population is a major issue for biofortification to be successful. To be accepted and cultivated by the farmers, the new variety must exhibit a high yield and resistance against disease and pests, in short be profitable. Characteristics of the newly developed plant such as yield, micronutrient concentration and disease and pests resistance should be stable over different environments and climatic zones. Moreover, the level of micronutrients must have the potential to significantly improve human health and ensure an adequate mineral bioavailability (Nestel et al., 2006; Bouis and Welch, 2010).

Aims of micronutrient levels for biofortified crops are amount of $\mathrm{Fe}, \mathrm{Zn}$ and Vitamin $\mathrm{A}$ required, breeding target is combination of baseline and increment that is set to meet the specific dietary require of women and children, based on current consumption patterns. Biofortification conduct a solution in the hands of farmers, combining the micronutrient trait with other agronomic and consumption traits that farmers prefer.

After achieve the household's food needs, surplus biofortified crops make their manner into rural and urban retail outlets. Genotypic differences in keeping and concentrations of compounds that inhibit or enhance micronutrient bioavailability are considered. 


\section{Pathway for biofortification}

For biofortification to accomplish some factors have to be considered, beginning with the identification of the targeted population and finishing with the improvement of the nutritional status of this population. The "impact pathway for fortified crops" as suggested by Harvest Plus is divided into the following three stages: (1) Discovery, (2) Development and (3) Dissemination of the newly developed plant variety.

\section{Discovery}

The first stage starts with the identification of targeted populations, for that the biofortified crop should be developed. The targeted populations are not sometimes restricted to only one country and scatter over effects to other countries or areas have to be taken into consideration. The selection should be done with regard to the prosperity of micronutrient deficiencies, the production and consumption of the targeted crop and the proportion and importance of self and locally produced plants (Ortiz-Monasterio et al., 2007). Incomplete or missing data from national health surveys complicates the recognition of populations effected by micronutrient deficiencies in many cases (Zapata-Caldas et al., 2009). Moreover, to correctly approach the consumption of the targeted crop in a population, the availability of representative and dependable dietary intake data has to be implicit (Hotz and McClafferty, 2007).

\section{Development}

In the development stage mainly focuses on the development and testing of biofortified crops. An overview of crops directly undergoing the biofortification process the identification of promising lines by breeders is followed by mapping of genotypic differences. New varieties are developed by crossing promising lines and selecting those with favourable characteristics over many generations (Grusak and Cakmak, 2004). The performances of the newly developed biofortified varieties are then tested over different environments, to evaluate genetic and environment (GxE) interactions. It is suggested that the variability of micronutrients in the germplasm depends on the genotype, the environment and $\mathrm{GxE}$ interaction, but the impact of the various factors differs between the micronutrients and crops. Formerly the desired variety is developed; the consumer acceptance in terms of taste, look and cooking quality is evaluated (Khoshgoftarmanesh et al., 2010) (Fig. 1).

\section{Dissemination}

In dissemination step the performance of the new variety in terms of micronutrient retentively is tested, followed by the examination of micronutrient bioavailability in humans. If results from these preliminary tests are superior, the performance of the new variety is investigated in an efficacy trial in human subjects, which is usually execute as a follow up study to an absorption study. Efficacy trials aim at investigation whether an intervention produces the expected results under ideal conditions. This is why efficacy trials are very closely monitored, wellcontrolled and conducted by highly trained specialists (Hallfors et al., 2006). They require an exacting research design including a specified and standardized treatment within standardized settings (Flay et al., 2005). Subjects often belong to a narrowly defined, homogenous group, who should be part of the targeted population. It has to be that the participants accept and fulfil with the treatment (Glasgow et al., 2003).

If the outcome of the efficacy trial is positive, in this step, the impact of the new variety on human health status is evaluated in an 
effectiveness trial. In this type of study, the beneficial effects of the crop are tested under conditions assume reality (Gartlehner et al., 2006). This is generally done among a broadly defined population which is representative for the targeted population.

The food is prepared and eaten in traditional ways within the usual household environment. Standardization only takes places in terms of accessible and availability of the biofortified crop among the population. To be certain that a crop is ready for dissemination, an effectiveness trial should be implemented since the outcome might be different from the efficacy trial and hidden difficulties, such as lack of proper implementation or weak acceptance might be uncovered. It is arguable whether efficacy trials earlier to effectiveness studies are necessary if the latter meet the standards of efficacy trials.

\section{Approaches for biofortification}

Biofortification is a strategy that involves the use of plant breeding or agronomic practices to increase the density of essential nutrients in the edible part of staple crops.

Agronomic biofortification is a fertilizerbased approach that relies on soil and foliar application of micronutrients either alone or in combination with other fertilizers. It is well established that a Zn fertilizer strategy is an effective way to biofortify cereal crops with $\mathrm{Zn}$, but recurrent cost is involved (Cakmak and Kutman, 2018).

Genetic biofortification is a strategy that uses plant breeding techniques to produce staple food crops with higher micronutrient levels, reducing levels of anti-nutrients and increasing the levels of substances that promote nutrient absorption.

\section{Agronomic biofortification}

The soils of the world are highly diverse, ranging from some of the oldest soils to relatively young volcanic soils in the Great Rift Valley that splits East and Southern Africa and alluvial soils along rivers. Many soils in the world suffer from multiple micronutrient deficiencies, due both to their poor inherent soil properties and to continuous cropping without nutrient restore. Contemporary fertilization programmes in many countries, primarily focus on NPK fertilizers, but many soils are non-responsive to NPK due to (multiple) micronutrient deficiencies. Soil amendment with small amounts of (multiple) micronutrients has been suggested as a sustainable strategy to increase yields and nutritional quality of crops (Voortman and Bindraban, 2015; Manzeke et al., 2012).

In the prevail paragraphs we discuss the impact of different fertilization approaches on agronomic biofortification, as well as the interactions of micronutrients with NPK fertilizers and the importance of Integrated Soil Fertility Management (ISFM).

\section{Impact of different fertilization techniques}

Foliar fertilization with micronutrients often restorative more nutrient uptake and efficient allowance in the edible plant parts than soil fertilization, especially with cereals and leafy vegetables (Lawson et al., 2015). Seed priming and seed coating with fertilizers are other approach for exact micronutrient application, that can encourage plant development and increase yields, but increased nutritional values of grains are infrequently found (Duffner et al., 2014). The combination of soil and foliar application is often the most effective method (Phattarakul et al., 2012; Cakmak, 2010). The downside of foliar application is that fertilizers can easily 
be washed off by rain and are costlier and difficult to apply (Garcia-Banuelos et al., 2014).

\section{Impact in combination with NPK fertilization}

Combination of micronutrients with macronutrients can influence the success of agronomic biofortification (Prasad et al., 2014). This results in increased micronutrient uptake and concentrations in the edible parts of the crop, as shown in wheat experiments, where high $\mathrm{N}$ application increased $\mathrm{Zn}$ and $\mathrm{Fe}$ concentrations in the grain endosperm (Kutman et al., 2011; Shi et al., 2010). Rao et al., (2012) observed that nutrient uptake (N, $\mathrm{P}, \mathrm{Zn}, \mathrm{B}, \mathrm{S})$ and productivity of sorghum and finger millet were increased significantly by fertilization with combine of mineral NPK plus Zn, B and S. However, P fertilization can also decrease micronutrient concentrations due to a dilution effect when plants grow productive (Singh et al., 1988). As indicated above, addition of $\mathrm{P}$ fertilization can also disclose incipient $\mathrm{Zn}$ deficiency by precipitation of insoluble $\mathrm{Zn}$ phosphate. Proper $\mathrm{N}$ and $\mathrm{P}$ management is important for the effectiveness of micronutrient fertilization and indicates the importance of a more integrated soil fertility management.

\section{Impact of integrated soil fertility management}

A consistently strategy suggested to optimize soil conditions is Integrated Soil Fertility Management which is defined as "a set of soil fertility management practices that necessarily include the use of mineral fertilizer, organic inputs and improved germplasm" (Vanlauwe et al., 2010). The combination of mineral fertilizers and organic inputs is beneficial, because they have complementary functions and enhance mutual effectiveness. Organic resources (plant residues and animal manure) help to sustain soil organic matter with multiple benefits in terms of enhanced soil structure, cation exchange capacity and water holding capacity (Van Noordwijk et al., 1997).

The application of micronutrient-enriched fertilizers should have no significant negative environmental effect when used at appropriate rates and generally has agronomic benefits as it improves soil fertility and crop health. Agronomic biofortification can be effective in increasing yields and nutritional quality for certain crop-micronutrient combinations, especially $\mathrm{Zn}$ and Se on wheat and maize, whereas Fe has shown little potential to era (Hussain et al., 2010).

\section{Genetic biofortification}

Conventional breeding and genetic engineering techniques both are approaches that may be used to increase micronutrient like iron, zinc and vitamin in biofortify crops (Tiwari et al., 2010). Cereals are the most important source of calories in human's body. Rice, wheat and maize provide about $23 \%$, $17 \%$ and $10 \%$, respectively, of the calories acquired globally (Khush, 2003). To effectively target biofortification of cereals, five key steps can be targeted. These are (a) enhanced uptake from soil, (b) increased transport of micronutrients to grains, (c) increased sequestration of minerals to endosperm rather than husk and aleurone, (d) reduction in anti-nutritional factors in grains and (e) increase in promoters of mineral bioavailability in grains. Biofortified crops are also a good source of reaching rural populations who may have limited access to diverse diets or other micronutrient interventions. The Consultative Group on International Agricultural Research (CGIAR) through its HarvestPlus initiative has been exploring the genetic variability, heritability of mineral traits, stability over different 
environments, genetic studies and breeding strategies to enhance the mineral content in major edible crops such as wheat, rice, maize, beans and cassava (CIAT/IFPRI, 2002).

Biofortification conventional plant breeding and genetic engineering both involve changing the genotype of targeted crops with the target of developing plants containing genes that support the accumulation of bioavailable minerals. The way of reaching this goal differs between the both approaches (Gomez-Galera et al., 2010). Currently work done on traditional plant breeding techniques which are exploiting the variability of micronutrient concentrations found in different germplasm (Qaim et al., 2007). In selective plant breeding programs search for variation in the character of desired, for example, higher iron content, within existing varieties of the crop. This characteristic is then bred into cultivated varieties by crossing (advisedly interbreeding) and selecting those individual plants with the desired characteristics.(1) Seed banks - collections of seeds usually collected in the past, which may have greater genetic variation than current varieties.(2) Mutagenesis - a chemical or physical induction of genetic mutations used to create new variation.(3)Wide crosses inter-breeding between a cultivated species and another, normally closely-related species.

Genetic engineering, used when crops have not the genetic potential to meet desired micronutrient levels with traditional plant breeding, and therefore it has to be applied to achieve sufficient improvements (Borg et al., 2009). A step change in our ability to biofortify crops has come from a much better understanding of how plants take up and distribute micronutrients, mainly through the identification of genes for mineral transport and the biosynthesis of organic metal chelators. This knowledge has been exploited in modern biotechnology approaches, demonstrating that it is possible to increase iron and zinc levels, not only in the whole grain but also specifically in the starchy endosperm. The proof-of-concept of transgenic approaches was initially demonstrated in rice. Increased expression of NAS-3, one of three genes encoding nicotianamine synthase (NAS), led to a 2.2-fold increase in the concentration of zinc and a 2.9-fold increase in the concentration of iron in the grain (Fig. 2).

So, the genetic modification is an excellent approach to gain high micronutrient concentrations (Bouis et al., 2010) and that genetically modified organisms (GMO) have the potential for increased agricultural productivity. A positive factor is the fast development and stable expression of GMO traits, to receive the desired new variety far fewer breeding generations are needed with genetic engineering compared to traditional plant breeding. Additionally, genetic engineering is more precise since single genes can be introduced in the targeted plants. But usually patented inventions are associated with the developed GMOs, making them inaccessible for researchers in developing countries and unaffordable for farmers (Pardey et al., 2000). Aside from numerous regulatory and political restrictions, transgenic plants often have to face social and ethical considerations causing a certain resistance to them (WHO, 2005).

Transgenic breeding could be another option in improving food crops with micronutrients. Generally, impressive progress is being made in developing transgenic plant genotypes with increased concentrations of $\mathrm{Zn}$ and Fe. Evidence is available showing a potential role of ZIP family that is $\mathrm{Fe}$ and $\mathrm{Zn}$ transporter proteins in improving micronutrient density in grain (Schachtman and Barker, 1999; Eide, 2006). These proteins are involved in uptake and transport of cationic micronutrients in 
cells. In most cases, the genes encoding the $\mathrm{Fe}$ and $\mathrm{Zn}$ transporter proteins are expressed in response to $\mathrm{Fe}$ and $\mathrm{Zn}$ deficiencies, respectively. However, the role of these transporter proteins in genotypic variation for $\mathrm{Zn}$ deficiency tolerance or grain $\mathrm{Zn}$ accumulation is not clear.

Harvest Plus: It was launched in 2004 with funding from the Bill and Melinda Gates Foundation the UK Department for International Development (DFID) and others. In this focusing on increasing levels of iron, zinc and beta-carotene in seven staple crops, grown in areas of high subsistence farming, namely sweet potato, bean, pearl millet, cassava, maize, rice and wheat. Main target of HarvestPlus is to obtain a new wheat variety by crossing high micronutrient wheat varieties with modern wheat (short stems and husk free). The newly developed wheat plant is expected to contain 40-50\% more iron and zinc than currently cultivated varieties (HarvestPlus, 2006). However, depending on wheat intake targeted levels might be lower than the levels recommended by WHO for wheat flour fortification. To improve iron status flour fortification levels should deliver about $6 \mathrm{mg}$ additional iron in the form of ferrous sulphate. Biofortified wheat varieties would deliver only about $1 \mathrm{mg}$ additional iron per $100 \mathrm{~g}$ wheat flour $(40 \%$ losses due to milling).

\section{Wheat}

A breeding program goals development of new genotypes with high $\mathrm{Zn}$ concentration first requires actuality of useful genetic variation for $\mathrm{Zn}$ accumulation in grain. However, as indicated above, cultivated wheat contain very low levels of $\mathrm{Zn}$ and shows a narrow genetic variation for $\mathrm{Zn}$. But the wild and primitive wheat cultivars represent a better and more promising genetic resource for high $\mathrm{Zn}$ concentrations. Among wild relatives tested so far, the collections of wild emmer wheat (Triticum turgidum ssp. dicoccoides,) showed massive genetic variation and the highest concentrations of $\mathrm{Zn}$ (14 to $190 \mathrm{mg} \mathrm{Zn} \mathrm{kg}^{-1}$ ). Very recently, new wild emmer wheat accessions have been identified showing simultaneously very high concentrations of $\mathrm{Zn}$ (up to $139 \mathrm{mg} \mathrm{kg}^{-1}$ ), Fe (upto $88 \mathrm{mg} \mathrm{kg}^{-1}$ ) and protein (up to 380 $\mathrm{g} \mathrm{kg}^{-1}$ ) in seeds and high tolerance to drought stress and $\mathrm{Zn}$ deficiency in soil (Peleg et al., 2008). In addition, synthetic wheats derived from Aegilops tauschii have also a high genetic potential for increasing grain $\mathrm{Zn}$ concentration of cultivated wheat (Calderini and Ortiz-Monasterio, 2003).

More than 3000 lines have been screened for $\mathrm{Fe}$ and $\mathrm{Zn}$ with concentrations for iron ranging from $25 \mu \mathrm{g}$ to $56 \mu \mathrm{g}$ per $\mathrm{g}$ wheat and for zinc ranging from $25 \mu \mathrm{g}-65 \mu \mathrm{g} / \mathrm{g}$ wheat. They observed high 16 Biomedicine and Biotechnology G X E Interactions for zinc and iron and low $\mathrm{G} \times \mathrm{E}$ interactions for $\mathrm{Mg}$ and suggested that breeding for high concentrations of $\mathrm{Fe}$ and $\mathrm{Zn}$ might be difficult. Substantial impact of $G \times E$ interactions on mineral concentration was confirmed by a recently conducted study in India (Joshi et al., 2010), and it is suggested that genetic factors for zinc and iron concentration in the wheat plant are of minor importance. Recreated synthetics, wild and landraces are being used as Progenitor for high $\mathrm{Zn} / \mathrm{Fe}$ Limited backcross approach to introgression high $\mathrm{Zn}$ genes into elite wheat Selected bulk scheme- Most effective method, non-destructive XRF machine being used for fast-track $\mathrm{Zn} / \mathrm{Fe}$ analysis.

\section{Biofortified varieties in wheat:}

WB 02: It is pure line variety, developed by ICAR- Indian Institute of Wheat and Barley Research, Karnal. Contain high iron (40 ppm) and zinc (42 ppm) as compared to $32 \mathrm{ppm}$ 
zinc and 28-32 ppm iron in popular varieties. Grain yield $51.6 \mathrm{q} / \mathrm{ha}$, maturity 142 days, it is timely sown irrigated variety. It adapted in Punjab, Haryana, Rajasthan and UP etc.

HPBW 01: Pure line variety developed at Punjab Agricultural University, Ludhiana. It contains high iron (40) and zinc (40.6) in comparison to 28-32 ppm iron and $32 \mathrm{ppm}$ zinc in popular varieties. It also adapted in Punjab, Rajasthan, Haryana, HP and Uttarakhand (Ref. ICAR New Delhi 2017).

\section{Pearl millet}

India, which has the largest pearl millet area about $>9$ million hectare in the world. Pearl Millet, as a species, has higher levels of $\mathrm{Fe}$ and $\mathrm{Zn}$ densities than other major cereal crops. Thus, there is a need to increase the cultivation of hybrids having higher $\mathrm{Fe}$ and $\mathrm{Zn}$ levels and enhance their consumption to better address various health problems associated with the deficiencies of these micronutrients. High-yielding open pollinated varieties (OPVs) and hybrids with higher levels of $\mathrm{Fe}$ and $\mathrm{Zn}$ densities than those found in most of the commercial cultivars otherwise not bred for these micronutrients as target traits have been developed and are available for commercialization (Rai et al., 2014).

Breeding lines and germplasm with still higher levels of Fe and $\mathrm{Zn}$ densities have been identified. Their utilization in breeding has the potential to enable development of hybrids with $>75$ ppm Fe density and $>55$ ppm $\mathrm{Zn}$ density. The primary focus of pearl millet biofortification is on improving $\mathrm{Fe}$ density with $\mathrm{Zn}$ density as an associated trait. Depending on the genotypic composition of the trials, moderate to high correlations between $\mathrm{Fe}$ and $\mathrm{Zn}$ densities have been observed, indicating good prospects of simultaneous genetic improvement for both traits, but perhaps also the need to make conscious selection for $\mathrm{Zn}$ density along with $\mathrm{Fe}$ density. Lack of association of $\mathrm{Fe}$ and $\mathrm{Zn}$ densities with grain size showed that both micronutrients can be improved without compromising on seed size. The association of $\mathrm{Fe}$ and $\mathrm{Zn}$ densities with grain yield was weak and negative, but not always significant, indicating that both micronutrients can be improved without significantly compromising grain yield by using large segregating populations.

Breeding Approach, the pearl millet biofortification breeding program at ICRISAT has taken a three-pronged breeding Phase-I, II and III. The first phase is a short-term approach dealing with traits genetics, germplasm screening and creating genetic variability. The second phase is the mediumterm approach consisting of validating identified high-iron and zinc breeding lines and hybrid parents from the regular breeding program to develop fast-track biofortified variety/hybrids. The third phase consisted of long-term objective- development high-Fe/Zn breeding lines and hybrid parents and its genetic diversification through steady mainstreaming micronutrient traits at ICRISAT and NARS breeding programs (Govindaraj and Rai 2016,). Currently, the pearl millet biofortification is in a gradual transition from fast-track breeding (breed incurrent breeding eff orts in the public and private sector are towards hybrid development and indeed supported by ICRISAT through the development and dissemination of a large number and diverse range of improved breeding lines and hybrid parents through Pearl Millet Hybrid Parent Research Consortia (PMHPRC). By utilizing identified high-Fe hybrid-parents from amongst those initially not bred for high-Fe as a target trait, several high-yielding and high-Fe hybrids have been developed, which are at various stages of testing. One such hybrid has been identified and designated as ICMH 1201, 
which in 48 field trials during 2011-2013 gave a $75 \mathrm{mg}$ per $\mathrm{kg}$ Fe density (similar to
ICTP8203) but had $3.6 \mathrm{t}$ ha-1grain yields (38\% higher than ICTP 8203).

Fig.1 Crop development framework. (Source: Harvest Plus)

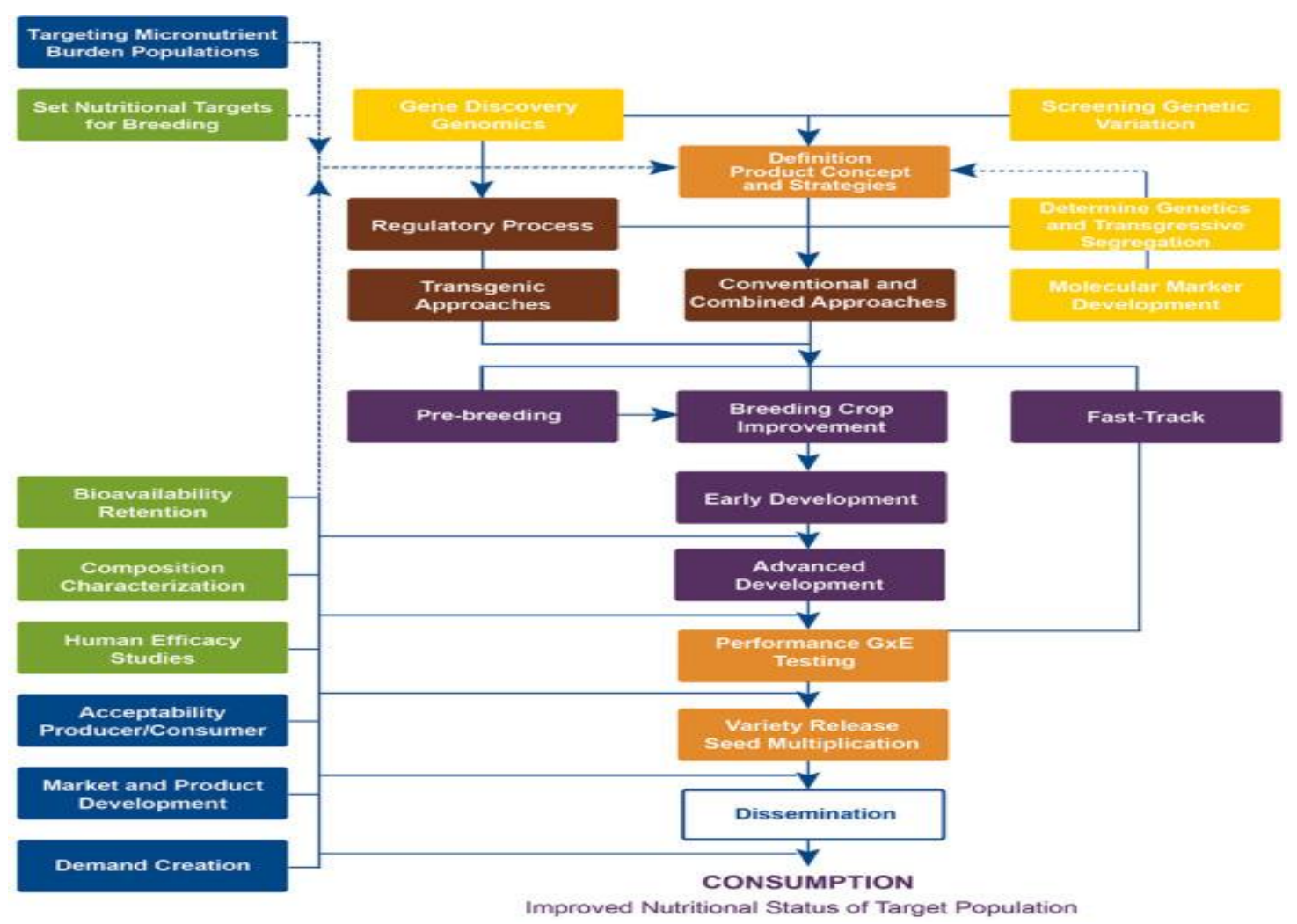

Fig.2 Characteristics of the original and reconstituted version of hybrid. A: Vivek Hybrid-9; B: Improved Vivek Hybrid-9 (Ref. Researchgate.net)

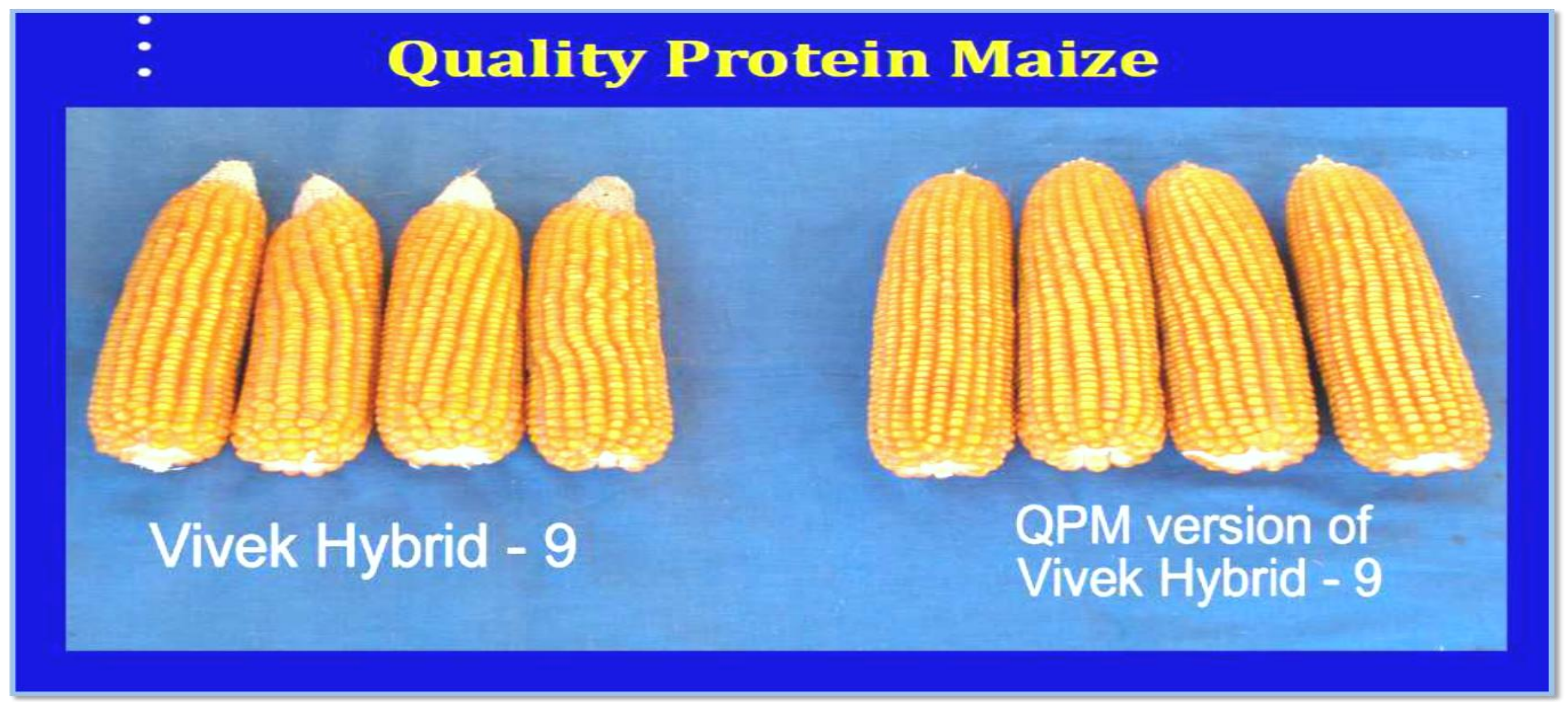


At ICRISAT, biofortified fast-track hybrids/varieties are developed through the XRF machine. Currently ICRISAT demonstrated the combining micronutrients and grain yield by conventional breeding approaches.

\section{Biofortified hybrid varieties in pearl millet}

HHB 299: Developed at CCS-Haryana Agricultural University, Hisar in collaboration with ICRISAT. Contains high iron $(73 \mathrm{ppm})$ and zinc (41 ppm) as compared to $45-50 \mathrm{ppm}$ iron and 30-35 ppm zinc in popular varieties/hybrid. Grain yield 32.7 q/ha, dry fodder yield 73 q/ha, maturity 81 days.

AHB 1200: It developed, by Vasantrao Naik Marathwada Krishi Vidyapeeth Parbhani with ICRISAT. Rich in iron (73 ppm) in comparison to $45-50 \mathrm{ppm}$ in popular hybrids. Grain yield 32 q/ha, dry fodder yield 70 q/ha, maturity 78 days (Ref. ICAR 2017).

\section{Rice}

Rice (Oryza sativa L.), one of the most important food crops in the world, forms the staple diet of over $50 \%$ of the world population. Billions of people in developing countries suffer from a lack of micronutrients in their daily food, a form of hunger also known as hidden hunger.

Micronutrient malnutrition especially $\mathrm{Fe}$ and $\mathrm{Zn}$ deficiency is recognized as a massive and rapidly growing public health issue mainly among poor people living on an unbalanced diet dominated by a single cereal such as rice (Brar et al., 2011).

The natural variation of iron in rice is quite low and milling and polishing usually results in a loss of up to $80 \%$ since iron is mainly stored in the aleurone layer and not in the endosperm. Iron and zinc concentrations in rice of different genotypes $(\mathrm{n}=1138)$ were found to range between $6.3-24.4 \mu \mathrm{g} / \mathrm{g}$ and 13.5- $58.4 \mu \mathrm{g} / \mathrm{g}$, respectively, suggesting that there is at least some genetic potential to successfully breed high mineral rice. Golden Rice was an important breakthrough in this direction as an effective source of provitamin A (beta-carotene) with a significant potential to reduce disease burden by expressing genes encoding PSY and carotene desaturase (Beyer et.al.2002). The level of beta-carotene precursor, i.e., phytoene, has been enhanced up to 23-fold by targeting gene encoding carotene desaturase. Folic acid (vitamin B9) is important for normal pregnancy and anaemia. Rice has been genetically modified to increase folate content (up to 150-fold) by overexpressing genes encoding Arabidopsis GTP-cyclohydrolase I (GTPCHI) and amino deoxychorismate synthase [ADCS], (Datta et.al. 2003)]. The $100 \mathrm{~g}$ of modified rice was found to be sufficient to meet daily folate requirements of an adult individual.

Breeding for high Zinc 3500 rice accessions, 100 popular lines have been screened, 14 genotypes with high $\mathrm{Zn}$ content in polished grains have been identified. Selection and phenotyping of 40 rice genotypes are under multi-location trails (Paine et al., 2005).

The development of the 'golden rice' proved that, it is possible to redirect a complete biosynthetic pathway of carotenoids by genetic engineering of multiple genes encoding key enzymes of the pathway. So, Golden Rice is such a biofortified it was developed in the year 2000 (Burkhardt, et al., 1997). To obtain a functioning provitamin A ( $\beta$-carotene) biosynthetic pathway in rice endosperm, we introduced in a single, combined transformation effort the cDNA coding for phytoene synthase (psy) and lycopene $\beta$-cyclase ( $\beta$-lcy) both from Narcissus pseudo narcissus and both under the control of the endosperm-specific glutelin 
promoter together with a bacterial phytoene desaturase (crtI, from Erwinia uredovora under constitutive $35 \mathrm{~S}$ promoter control). This combination covers the requirements for $\beta$-carotene synthesis and, as hoped, yellow $\beta$ carotene-bearing rice endosperm was obtained in the T0-generation. Additional experiments revealed that the presence of $\beta$ lcy was not necessary, because psy and crt I was able to drive $\beta$-carotene synthesis as well as the formation of further downstream xanthophylls. Plausible explanations for this finding are that these downstream enzymes are constitutively expressed in rice endosperm or are induced by the transformation, e.g., by enzymatically formed products.

Results using N., pseudo narcissus as a model system led to the development of a hypothesis, our present working model, that trans-lycopene or a trans-lycopene derivative acts as an inductor in a kind of feedback mechanism are stimulating endogenous carotenogenic genes.

\section{Varieties of biofortified rice}

CR Dhan 310 It is a pure line variety and contains high protein $(10.3 \%)$ in polished grains average grain yield is $45 \mathrm{q} / \mathrm{ha}$ (quintal/hectare), it matures in 125 days. This biofortified variety has been developed by ICAR-National Rice Research Institute, Cuttack, and Odisha.

DRR Dhan 45: It is a pure line variety and possesses high zinc $(22.6 \mathrm{ppm})$ in polished grain. Its average grain yield is $50 \mathrm{q} / \mathrm{ha}$; it matures in 125-130. This biofortified variety has been developed by ICAR-Indian Institute of Rice Research, Hyderabad, and Telangana.

DRR Dhan 49: It is a pure line variety with high zinc $(25.2 \mathrm{ppm})$ in polished grain its average grain yield is $50 \mathrm{q} / \mathrm{ha}$. It matures in 125-130 days. This biofortified variety has been developed by ICAR-Indian Institute of Rice Research, Hyderabad, and Telangana (Ref. ICAR 2017).

\section{Maize}

Maize is the staple food for more than 1.2 billion people worldwide, particularly in Latin America, Sub-Saharan Africa, and many of the South East Asian countries, including India. Maize lacks lysine and tryptophan necessary for protein synthesis. QPM contains a naturally-occurring mutant (opaque2) maize gene that increases the amount of those two essential amino acids. It produces $70-100 \%$ more of lysine and tryptophan than the most modern varieties, it reduces the incidence of pellagra, QPM is a product of conventional plant breeding i.e., it is not genetically modified (Atlin et al., 2011). Development of micronutrient-enriched staple plant foods through breeding holds significant promise for sustainable food-based solutions (Banziger and Long 2000, Graham et al., 2001, Pfeiffer and McClafferty, 2007).

Micronutrient-enriched or biofortified maize would not only serve as the logical vehicle for providing $\mathrm{Fe}$ and $\mathrm{Zn}$ in the diets of the people (Long et al., 2004) but also shall be a costeffective and sustainable approach to alleviate micronutrient deficiencies (Bouis, 2002). Development of micronutrient-rich cultivars would produce higher yield in a micronutrient-deficient soil than the micronutrient inefficient variety.

Kernel iron $(\mathrm{Fe})$ and zinc $(\mathrm{Zn})$ concentrations were evaluated in a set of 30 diverse maize genotypes during rainy (kharif) season of 2006, 2007 and 2008 (Prasanna et al., 2011). The ranges of kernel $\mathrm{Fe}$ and $\mathrm{Zn}$ concentrations were $11.28-60.11 \mathrm{mg} / \mathrm{kg}$ and $15.14-52.95 \mathrm{mg} / \mathrm{kg}$, respectively, across the three years. Based on the performance of the entries across the years, four highly promising 
inbreds and three landrace accessions were identified as highly promising for kernel $\mathrm{Fe}$ concentration, including a HarvestPlus line, HP2 (42.21 mg/kg).

Similarly, for kernel $\mathrm{Zn}$ concentration, three inbreds and one landrace were identified as highly promising, includingV340 (43.33 $\mathrm{mg} / \mathrm{kg}$ ). No significant association was found between kernel $\mathrm{Fe}$ and $\mathrm{Zn}$ concentrations indicating the need for independent selection for enhancing the concentration for these traits.

Development of vitamin A-rich cereals can help in alleviating the wide spread problem of vitamin A deficiency. We report here significant enhancement of kernel b-carotene in elite maize genotypes through accelerated marker-assisted backcross breeding (Muthusamy et al., 2014). A favourable allele (543 bp) of the b-carotene hydroxylase (crtRB1) gene was introgressed in the seven elite inbred parents, which were low (1.4 $\mathrm{mg} / \mathrm{g}$ ) in kernel b-carotene, by using a crtRB1-specific DNA marker for foreground selection.

About $90 \%$ of the recurrent parent genome was recovered in the selected progenies within two backcross generations. Concentration ofb-carotene among the crtRB1-introgressed inbreds varied from 8.6 to $17.5 \mathrm{mg} / \mathrm{g}$ - a maximum increase up to 12.6-fold over recurrent parent.

The reconstituted hybrids developed from improved parental inbreds also showed enhanced kernel b-carotene as high as 21.7 $\mathrm{mg} / \mathrm{g}$, compared to $2.6 \mathrm{mg} / \mathrm{g}$ in the original hybrid. There constituted hybrids evaluated at two locations possessed similar grain yield to that of original hybrids. These b-carotene enriched high yielding hybrids can be effectively utilized in the maize biofortification programs across the globe.

\section{Varieties of maize}

\section{Pusa Vivek QPM9 improved}

It is possessing high provitamin-A (8.15 ppm). It also contains high tryptophan $(0.74 \%)$ and lysine $(2.67 \%)$ in endosperm protein and known as 'quality protein maize' (QPM). This biofortified variety has been developed by ICAR-IARI, New Delhi.

\section{Pusa HM4 improved}

It is a QPM hybrid that possesses high tryptophan $(0.91 \%)$ and lysine $(3.62 \%)$ in endosperm protein. Its average grain yield is $64.2 \mathrm{q} / \mathrm{ha}$ and it matures in 87 days. This biofortified variety has been developed by ICAR-IARI, New Delhi.

\section{Pusa HM8 improved}

It is a QPM hybrid that possesses high tryptophan (1.06\%) and lysine $(4.18 \%)$ in endosperm protein. Its average grain yield is $62.6 \mathrm{q} / \mathrm{ha}$ and it matures in 95 days. This biofortified variety has been developed by ICAR-IARI, New Delhi (Ref. ICAR 2017).

In conclusion the biofortification of crops is a feasible and most economical approach for overcoming 'hidden hunger'. Increasing the concentration of minerals in edible portions of cereals involves better uptake from soil and improved translocation to grains from leaves and finally enhanced sequestration to endosperm. Genetic diversity can be utilized to enhance micronutrient composition through conventional and modern breeding approaches. The most promising work plan to successfully alleviate micronutrient malnutrition will be to increase mineral content in the crops and simultaneously enhance their bioavailability by reducing antinutritional compounds and enhancing concentration of mineral absorption 
promoters. To effectively combat hidden hunger through biofortification, even after the development of biofortified varieties, it will be essential to address various socioeconomical and socio political challenges to popularize their cultivation by farmers and ultimately their consumption by the end users. A multi-tier coordinated strategy will play a pivotal role in overcoming hidden hunger. Given the severity of mineral malnutrition in humans worldwide, bio-fortification of micronutrients, especially $\mathrm{Fe}$ and $\mathrm{Zn}$, in cereals must be encouraged. Although agronomic strategies (e.g., fertilizer strategy) can also increase micronutrient concentrations in cereal grains, however, there are still many challenges.

\section{References}

Allen, L.H., De Benoist, B., Dary, O., and Hurrell, R. 2006. Guidelines on food fortification with micronutrients. Geneva: WHO and FAO., 1-341.

Atlin, G.N., Palacios, N., Babu R., Das, B., Twumas-Afriyie S. 2011. Quality protein maize: Progress and prospects. Plant Breed Rev., 34: 83-130.

Banziger, M. and Long, J., 2000. The potential for increasing the iron and zinc density of maize through plantbreeding. Food and Nutrition Bullet., 21: 397-400.

Beyer, P., Al-Babili, S., Ye, X., Lucca, P., Schaub, P., Welsch, R. 2002. Golden rice: introducing the $\beta$-carotene biosynthesis pathway into rice endosperm by genetic engineering to defeat vitamin A deficiency Nutr. 132(3): 506S-10S.

Borg, S., Brinch-Pedersen, H., Tauris, B., and Holm, P.B. 2009. Iron transport, deposition and bioavailability in the wheat and barley grain. Plant and Soil., 325: $15-24$

Bouis, H.E., Graham, R.D., Welch, R.M.
2000. The Consultative Group on International Agricultural Research (CGIAR) Micronutrients Project: Justifications and objectives. Food Nutr. Bull., 21: 374-381.

Bouis, H.E. 2002. Plant breeding: a new tool for fighting micronutrient malnutrition. Journal of Nutrition., 132: 491S-94.

Bouis, H.E. 2003. Plant breeding: A new tool for fighting micronutrient malnutrition. Journal of Nutrition., 132 (3): 491S494S.

Bouis, H.E. and Welch, R.M. 2010. Biofortification: A Sustainable Agricultural Strategy for Reducing Micronutrient Malnutrition in the Global South. Crop Science., 50: S20-S32.

Brar, B., Jain, S., Singh, R. and Jain, R.K, 2011. Genetic diversity for iron and zinc contents in a collection of 220 rice (Oryza sativa L.) genotypes. Indian Journal of Genetics., 71(1): 67-73.

Brinch, P.H., Borg, S., Tauris, B., Holm, P.B. 2007. Molecular genetics approaches to increasing mineral availability and vitamin content of cereals. Journal of Cereal Science., 46: 308-326.

Burkhardt, P.K., Beyer, P., Wuenn, J., Kloeti, A., Armstrong, G.A. Schledz, M. 1997. Transgenic rice (Oryza sativa) endosperm expressing daffodil (Narcissus pseudonarcissus) phytoene synthase accumulates phytoene, a key intermediate of provitamin A biosynthesis. Plant J., 11:1071-8.

Cakmak, I., 2008. Enrichment of cereal grains with zinc: Agronomic or genetic biofortification. Plant Soil., 302:1-17.

Cakmak, I., Pfeiffer, W.H., McClafferty, B. 2010. Biofortification of durum wheat with zinc and iron. Cereal Chem., 87 (1): 10-20.

Calderini, D.F., and Ortiz Monasterio, I. 2003. Are synthetic hexaploids a means of increasing grain element concentrations in wheat. Euphytica., 
134: 169-178.

CIAT/IFPRI, 2002. Bio-fortified Crops for Improved Human Nutrition. An Challenge Program Proposal. Consultative Group on International Agricultural Research, Washington. Available at: http://www.cgiar.org/ biofortification.

Datta, K., Baisakh, N., Oliva, N., Torrizo, L., Abrigo, E., Tan, J. 2003. Bio engineered 'golden' Indica rice cultivars with beta-carotene metabolism in the endosperm with hygromycin and mannose selection systems. Plant Biotechnol J., 1:81-90.

Duffner, A., Hoffland, E., Stomph, T.J., Melse-Boonstra, A., Bindraban, P.S. 2014. Eliminating zinc deficiency in rice-based systems. VFRC Report 2014/2. Virtual Fertilizer Research Center, Washington, D.C.

Eide, D.J. 2006. Zinc transporters and the cellular trafficking of zinc. Biochim Biophys Acta., 1763: 711-722.

FAO, IFAD, and W. F. P. 2018. The State of Food Insecurity in the World 2015. Food and Agriculture Organization of the United Nations, Rome.

Flay, B., Biglan, A., Boruch, R., Castro, F., Gottfredson, D., and Kellam, S. 2005. Standards of Evidence: Criteria for Efficacy, Effectiveness and Dissemination. Prevention Science., 6: 20-26.

Garcia-Banuelos, M.L., Sida-Arreola, J.P., Sanches, E. 2014. Biofortification promising approach to increasing the content of iron and zinc in staple food crops. J. Elem., 19 (3): 865-888.

Gartlehner, G., Hansen, R.A. Nissman, D., Lohr, K.N, and Carey, T.S. 2006. Criteria for distinguishing effectiveness from efficacy trials in systematic reviews. AHRQ., 6-46.

Glasgow, R.E., Lichtenstein, E. and Marcus, A.C. 2003. Why don't we see more translation of health promotion research to practice? Rethinking the efficacy to effectiveness transition. American $J$. Public Health., 93: 1261-1267.

Gomez-Galera, S., Rojas, E., Sudhakar, D., Zhu, C.F. Pelacho, A.M. and Capell, T. 2010. Critical evaluation of strategies for mineral fortification of staple food crops. Transgenic Res., 19: 165180.

Govindaraj, M.; Rai, K.N. 2016. Breeding Biofortified Pearl Millet Cultivars with high iron density. Indian Farm., 65: 53-55.

Graham, R.D., Welch, R.M. and Boius, H. E. 2001. Addressing micronutrient malnutrition through enhancing the nutritional quality of staple foods: principles, perspectives and knowledge gaps. Advances in Agronomy., 70: 77142.

Grusak, M. and Cakmak, I. 2004. Methods to improve the crop-delivery of minerals to humans and livestock. International Workshop on Modelling Quality Traits and Their Genetic Variability for Wheat; Jul 18-21; Clermont-Ferrand., FRANCE.

Hallfors, D., Cho, H., Sanchez, V., Khatapoush, S., Kim, H.M. and Bauer, D. 2006. Efficacy vs effectiveness trial results of an indicated "model" substance abuse program: Implications for public health. Am J Public Health., 96: 2254-2259.

https://globalnutritionreport.org. The global prevalence of anaemia in Geneva: World Health Organization; 2015. Available online.

HarvestPlus, 2006. Bio-fortified Maize http://www.dfid.gov.uk/r4d/PDF/Outpu ts/Misc rop/maize. pdf: Houston

Hotz, C., Meenakshi, J.V., and McClafferty, B. 2008. Bio-fortification of staple crops: An emerging strategy to combat hidden hunger. Comprehensive Reviews in Food Science and Food 
Safety., 7: 329-334.

Joshi, A.K., Crossa, J., Arun, B., Chand, R., Trethowan, R., and Vargas, M. 2010. Genotype $\mathrm{x}$ Environment interaction for zinc and iron concentration of wheat grain in eastern Gangetic plains of India. Field Crop Research., 116: 268277.

Kassebaum, N. J., Jasrasaria, R., Naghavi, M., Wulf, S. K., Johns, N., Lozano, R. 2014. A systematic analysis of global anaemia burden from 1990 to 2010 . Blood 123, 615-624. doi 10.1182/blood-2013-06-508325.

Khoshgoftarmanesh, A.H., Schulin, R., Chaney, R.L, Daneshbakhsh, B., and Afyuni, M. 2010. Micronutrient efficient genotypes for crop yield and nutritional quality in sustainable agriculture. A review. Agron Sustain Development., 30: 83-107.

Khush, G. S. 2003: Productivity improvements in rice. Nutr. Rev., 61: S114-S116.

Kutman, U.B., Yildiz, B., Cakmak, I., 2011. Improved nitrogen status enhances zinc and iron concentrations both in the whole grain and the endosperm fraction of wheat. J. Cereal Sci., 53: 118-125.

Lawson, P.G., Daum, D., Czaudema, R., Meuser, H., Harling, J.W. 2015. Soil versus foliar iodine fertilization as a biofortification strategy for field-grown vegetables. Front. Plant Sci., 6: 450.

Long, J. K., Banziger, M. and Smith, M. E. 2004. Diallel analysis of grain iron and zinc density in Southern Africanadapted maize inbreds. Crop Science., 44: 2019-26.

Manzeke, G.M., Mapfumo, P., Mtambanengwe, F., Chikowo, R., Tendayi, T., Cakmak, I. 2012. Soil fertility management effects on maize productivity and grain zinc content in smallholder farming systems of Zimbabwe. Plant Soil., 361: 57-69.
Mayer, J.E., Pfeiffer, W.H., and Beyer, P. 2008. Bio-fortified crops to alleviate micronutrient malnutrition. Curr Opin Plant Biol., 11 (2):166-170.

Muthusamy, V., Hossain, F., Thirunavukkarasu, N., Choudhary, M. Saha, S. 2014. Development of bCarotene Rich Maize Hybrids through Marker-Assisted Introgression of bcarotene hydroxylase Allele. PLoS ONE 9(12): e113583. doi:10.1371/ journal. pone. 0113583 .

Nestel, P., Bouis, H.E., Meenakshi, J.V., and Pfeiffer, W. 2006. Bio-fortification of staple food crops. Journal of Nutrition., 136: 1064-1067.

Oliver, M. A., and Gregory, P. J. 2015. Soil, food security and human health: areview. Eur. J. SoilSci., 66: 257-276. doi: 10.1111/ejss.12216.

Ortiz-Monasterio, J.I., Palacios-Rojas, N., Meng, E., Pixley, K., Trethowan, R., and Pena, R.J. 2007. Enhancing the mineral and vitamin content of wheat and maize through plant breeding. Journal of Cereal Science.,46: 293-307.

Paine, J.A., Shipton, C.A., Chaggar, S., Howells, R.M, Kennedy, M.J, Vernon, G. 2005. Improving the nutritional value of golden rice through increased pro-vitamin A content. Nat Biotechnol., 23: 482-7. doi:10.1038/nbt1082.

Pardey, P.G., Wright, B.D., and Nottenburg, C. 2000. An Intellectual Property Rights Stifling Agricultural Biotechnology in Developing Countries? In: IFPRI (ed). Annual Report.

Pfeiffer, W.H., and McClafferty, B. 2007. Biofortification: Breeding Micronutrient-Dense Crops. In: Kang MS (Ed) Breeding major food staples. Blackwell Science Ltd.

Pfeiffer, W.H., and McClafferty, B. 2007. HarvestPlus: Breeding Crops for Better Nutrition. Crop Science., 47 (S3): S88S105. 
Phattarakul, N., Rerkasem, B., Li, L.J., Wu, L.H., Zou, C.Q., Ram, H., Sohu, V.S., Kang, B.S., Surek, H., Kalayci, M., Yazici, A., Zhang, F.S., Cakmak, I., 2012. Biofortification of rice grain with zinc through zinc fertilization in different countries. Plant Soil., 361: 131-141.

Prasad, A. S. 2013. Discovery of Human Zinc Deficiency: Its Impact on Human Health and Disease-Advances in Nutrition, 4(2): 176-190. Available at: https://academic.oup.com/advances/arti cle/4/2/176/4591626.

Prasad, R., Shivay, Y.S., Kumar, D. 2014. Chapter two - agronomic biofortification of cereal grains with iron and zinc. Adv. Agron., 125: 55-91.

Prasanna, B.M., Mazumdar, S., Chakraborti, M., Hossain, F. 2011. Genetic variability and genotype $\times$ environment interactions for kernel iron and zinc concentrations in maize (Zea mays) genotypes. Indian Journal of Agricultural Sciences., 81 (8): 704-11.

Qaim, M., Stein, A.J. and Meenakshi, J.V. 2007. Economics of bio-fortification. Agr Econ-Blackwell., 37: 119-133.

Rai, K.N., Patil, H.T., Yadav, O.P., Govindaraj, M., Khairwal, I.S., Cherian, B., Rajpurohit, B.S., Rao, A.S., Shivade, H., Kulkarni, M.P. 2014. Variety Dhanashakti (Pearlmillet). Indian J. Genet., 74: 405406.

Rao, B.K.R., Krishnappa, K., Srinivasarao, S.P., Wani, K.L., Sahrawat, K.L., Pardhasaradhi, G. 2012. Alleviation of multinutrient deficiency for productivity enhancement of rain-fed soybean and finger millet in semi-arid region of India. Commun. Soil Sci. Plant Anal., 43 (10): 1427-1435.

Schachtman, D.P., Barker, S.J. 1999. Molecular approaches for increasing the micronutrient density in edible portions of food crops. Field Crop Res., 60: 81-92.

Shi, R., Zhang, Y., Chen, X., Sun, Q., Zhang, F., Römheld, V., Zou, C., 2010. Influence of long-term nitrogen fertilization on micronutrient density in grain of winter wheat (Triticum aestivum L.). J. Cereal Sci.., 51 (1): 165-170.

Singh, J.P., Karamanos, R.E., Stewart, J.W.B., 1988. The mechanism of phosphorus induced zinc deficiency in bean (Phaseolus vulgaris L.). Can. J. Soil Sci. 68: 345-358.

Tanumihardjo, S.A., Bouis, H., Hotz, C., Meenakshi, J.V., and McClafferty, B., 2008. Bio-fortification of staple crops: An emerging strategy to combat hidden hunger. Comprehensive Reviews in Food Science and Food Safety., 7: 329334.

Tiwari, V. K., N. Rawat, K. Neelam, S. Kumar, G. S. Randhawa, and H. S. Dhaliwal. 2010. Substitution of 2S and 7U chromosomes of Aegilops kotschyi in wheat enhances grain iron and zinc concentration. Theor. Appl. Genet., 121: 259-269.

Underwood, B. A. 2000. Overcoming micronutrient deficiency in developing countries: is there a role for agriculture? Food Nutr. Bull. 21: 356-360. doi: 10.1177/156482650002100403.

Vanlauwe, B., Bationo, A., Chianu, J., Giller, K.E., Merckx, R., Mokwunye, U., Ohiokpehai, O., Pypers, P., Tabo, R., Shepherd, K.D., Smaling, E.M.A., Woomer, P.L., Sanginga, N., 2010. Integrated soil fertility management Operational definition and consequences for implementation and dissemination. Outlook Agric.39, 1724.

Van Noordwijk, M., Cerri, C., Woomer, P.L., Nugroho, K., Bernoux, M., 1997. Soil carbon dynamics in the humid tropical 
forest zone. Geoderma 79, 187-225.

Voortman, R., Bindraban, P.S., 2015. Beyond $\mathrm{N}$ and P: Toward a land resource ecology perspective and impactful fertilizer interventions in sub-Saharan Africa. VFRC Report 2015/1. Virtual Fertilizer Research Center, Washington, DC.

Welch, R.M. and Graham, R.D. 2015. Breeding for micronutrients in staple food crops from a human nutrition perspective. Journal of Experimental Botany., 55: 353-364.

Wessells, K. R., Singh, G. M., and Brown, K. H. 2012. Estimating the global prevalence of inadequate zinc intake from national food balance sheets: effects of methodological assumptions. PLoS ONE 7: e50565. doi: 10.1371/journal.pone.0050565.

White, P. J. and Broadley, M. R. 2009. Biofortification of crops with seven mineral elements often lacking in human diets - iron, zinc, copper, calcium, magnesium, selenium and iodine. New Phytol., 182: 49-84.

WHO, 2005. Modern food biotechnology, human health and development: an evidence based study: Geneva.

Zapata-Caldas, E., Hyman, G., Pachón, H., Monserrate, A., and Varela, L.V. 2009. Identifying candidate sites for crop biofortification in Latin America: case studies in Colombia, Nicaragua and Bolivia. International Journal of Health Geographics., 54(2): 234-238.

\section{How to cite this article:}

Madhu Choudhary and Rajwanti Saran. 2020. A Review on Biofortification - To Improve Nutritional Quality of Cereals Int.J.Curr.Microbiol.App.Sci. 9(09): 2406-2423. doi: https://doi.org/10.20546/ijcmas.2020.909.301 